\title{
LAS SECUELAS DEL EXILIO CUBANO: DESTERRADOS AL FUEGO DE MATÍAS MONTES HUIDOBRO
}

\author{
Luis A. Jiménez
}

\begin{abstract}
RESUMEN
En este ensayo se discuten las secuelas experimentadas por el refugiado cubano en los Estados Unidos. Se analizan estas consecuencias en términos de su identidad cultural y lingüística, los efectos psicológicos y existenciales, al igual que su manera de vestir. Sobre este último apartado se examina el abrigo del protagonista-narrador, ya que la vestimenta se convierte en el leit-motif de la novela y sin este ropaje el texto de Montes Huidobro no existiría.

Palabras clave: éxodo, refugiado cubano, sincronía, identidad, moda.
\end{abstract}

\begin{abstract}
In this essay we discuss the sequelae experienced by the Cuban refuge in the United States. We analyze these consequences in terms of his cultural and linguistic identity, the psychological and existential effects as well as his way of dressing. Within this last section we examine the protagonist-narrator's overcoat, since this garment becomes the leit-motif of the novel and without the vestiment Montes Huidobro's text would not exist.

Key words: exodus, Cuban refugee, synchrony, identity, fashion.
\end{abstract}

Más que un enclave miamense, el exilio cubano, provocado por el régimen castrista, se ha bifurcado en una institución global que no solamente se ha dispersado por el resto de los Estados Unidos, sino que también se ha esparcido en gran número por Europa y América Latina, e inclusive hasta Australia y Japón en menor grado. Por dondequiera, existen muchos más espacios desde donde los desterrados han sufrido las ráfagas del destino que nos ha impuesto el sanguinario dictador.

Dr. Luis A. Jiménez. Catedrático de la Universidad de Tampa, Florida.

Correo electrónico: ljimenez@ut.edu

Recepción: 22- 04- 2011

Aceptación: 30- 05- 2011 
La literatura dedicada al destierro cubano consta de una bibliografía extendidísima e inacabable que sería imposible elaborar debido a las limitaciones de este enfoque crítico. Sin embargo, se podrían citar algunas de sus secuelas: la búsqueda de la "Otredad" en un proceso identitario, los efectos psicológicos e existenciales irreparables que han causado y hasta el cambio en el modo de vestir de los primeros ex-patriados en la primera ola exílica dentro de los signos de otra cultura distinta. Son todos estos, y muchos más, factores imprevisibles de los que tocamos tierra de libertad y que aparecen en la novela Desterrados al fuego de Matías Montes Huidobro y de la que nos ocuparemos en este estudio, sobre todo, el tema liminar de lo que el narrador llama "el penoso período del abrigo" (1975: 17) ${ }^{1}$. Dicho abrigo se transforma diegéticamente en el leit-motif de la obra porque sin este el texto no existiría.

Cuando comenta sobre el historicismo de la literatura del exilio, Edward Said la asocia al sentido de soledad, la expresión de sentimientos de emociones privadas, la pérdida de identidad y el miedo neurótico (1990: 357-66); síntomas vinculados a la condición de expatriado $^{2}$. Más específicamente con respecto a la literatura exílica cubana, Isabel Alvarez Borland afirma que la "experiencia física del éxodo" exhibe la indignación y la ira hacia los "eventos traumáticos o individuales" (1998: 7) que causaron el exilio. Añade que la presencia del país adoptivo no es central a la narrativa de estos escritores, alegato que en realidad no se sostiene en Desterrados al fuego, a pesar de la perspectiva nostálgica que la impulsa ${ }^{3}$.

Al comienzo de la narración el protagonista narrador, cuyo nombre nunca se menciona, y su esposa Amanda se movilizan, al igual que millares de cubanos, en su preparación hacia el éxodo masivo suscitado por el triunfo de la revolución cubana. En la mente del personaje, se graban dos pertenencias vitales para él: la máquina de escribir y el traje de novia de Amanda. En cuanto al primer artículo, se justifica la inherencia intelectual ceñida a sus ambiciones de escribir, particularmente al deseo de ser novelista. El vestido de boda, por otro lado, abre el cofre de la memoria a un valor sentimental con un gesto espiritual muy marcado en el discurso.

Mencionemos que en la producción literaria de Montes Huidobro el acto de rememorar cumple un funcionamiento operable en su estética personal como escritor ${ }^{4}$. Metonímicamente hablando, los dos objetos representan un engarce de la escritura con el entorno familiar e intelectual del pasado. De conformidad con la sinécdoque, los artículos acusan el idilio perdido en Cuba.

Formulemos ahora la observación semántico-histórica del narrador dentro de los códigos gramaticales que conciben el proceso metonímico, debido a la fragmentación del lenguaje. Si la gramática se divide en unidades sintácticas, también el vestuario se fragmenta en sus partes constitutivas: el traje de novia de Amanda, por ejemplo. Esta vestimenta se acoge a códigos y reglas sujetos a cambios que van de acuerdo con el estilo de la época de una cultura, lo que obliga a emplearlos. Por esta razón, el vestido de la esposa no constituye en sí una pérdida material para el protagonista, sino que le ocasiona cierto disgusto emotivo debido a la constitución sígnica del lenguaje. De todos modos, pendiente del esperpentismo de la realidad nacional, el narrador opina que este traje no adquiere ningún significado social dentro de los parámetros del historicismo marxista: "Nos imaginamos que sufriera penosas adaptaciones aunque dudamos que fuera utilizado en ninguna otra boda" (10).

En la posmodernidad literaria, se profundiza el fenómeno de la nostalgia al devenir temporal que evoca vivencias pretéritas. Si se toma en cuenta la etimología de la palabra, el término proviene del griego nóstos que significa un retorno al pasado, una vuelta a la patria y a las pertenencias que se dejan en ella: el ejemplo de la máquina de escribir y el traje de bodas 
de Amanda. También lo posmoderno implica un cruce cultural y lingüístico de fronteras que afecta al recién arrivado a tierras foráneas tal y como le ocurre al protagonista de la novela de Montes Huidobro.

En términos de sustancia temática, la retórica del ropaje en Desterrados al fuego se traduce en un lenguaje inscrito al proceso de significación y al de diferenciación. Importa anotar que ambos procesos constituyen la consecuencia irremediable de la existencia fragmentaria en el futuro del desterrado aferrado a su pasado en la Isla. La preocupación esencial del narrador en este caso difiere del metalenguaje de revistas, periódicos y otros medios de comunicación en los que esta vestimenta se transforma en objeto visual del momento sincrónico de la moda. La reacción del protagonista, por el contrario, se centra en un acto diacrónico conmemorativo que evoca el vestido de boda, otro proceso sígnico desplegado repetidamente en la novela, y signo cercano a la voluntad individual o social.

A través de los siglos, el sujeto humano se ha comunicado con otros por medio del lenguaje de la ropa, que a lo largo de diferentes épocas se ha transformado en un sistema de signos (Lurie 1992: 3). Desde la perspectiva semiótica y apoyado en los planteamientos saussurianos, Roland Barthes en The Language of Fashion establece una distinción tajante entre el lenguaje y la palabra. Al referirse al primer vocablo, expone que este constituye un sistema subyacente a una institución socio-cultural independiente del sujeto, mientras que el segundo es un acto individual (2006: 8). Para nuestra exégesis, la palabra vestimenta, o sea el abrigo negro de lana del personaje en Desterrados al fuego, difiere en su totalidad del vestir, la manera que el lenguaje estricto de la moda se actualiza sincrónicamente en una era definida 5 .

Consciente de la recepción del libro, Montes Huidobro satura su práctica textual de huellas legibles por medio de las cuales el lector participa y se confabula con los hechos contados por el narrador ${ }^{6}$. No pretendemos aquí insistir en la función pecunaria del abrigo porque en realidad no existe y podría exacerbar la paciencia del destinatario de la novela. En varias ocasiones, el protagonista subraya una creciente dependencia del interlocutor tal y como se nota en este enunciado seleccionado: "No se crea el impaciente lector que esta insistencia mía [en la higiene] resulta una penosa digresión novelesca que me aleja del tema [del abrigo]" (14). De hecho, el receptor del texto ya ha sido informado con anterioridad de la carencia monetaria del objeto; aclaramos que se debe al poco valor de las mercancías en la Cuba de la revolución castrista.

Por ello, simplemente se intenta abarcar el sentido precario del desterrado que sale con tres mudas en el equipaje rústico del "gusano" y cómo se adapta a los limitados artículos de ropa que tiene a su disposición en el exilio y que, según el narrador, "restaban por completo, fuera de moda" (12). Este detalle del lenguaje del vestir que pudiera ser insignificante crea una barrera identitaria para el grupo de los recién llegados ${ }^{7}$, una dislocación traumática de la relación entre el individuo y la sociedad que lo acoge. Después de todo, ¿no es el exilio una categoría cultural? (Abellán 1987: 42-57). El protagonista de la novela responde sobre la amenaza del concenso colectivo de la siguiente manera: "Nuestra manera de vestir, arcaica, obsoleta, nos hacía parecer un poco raros, como si procediéramos de algún extraño planeta" (12). En el tanteo crítico del plantemiento, afirma que en la conciencia de los desterrados "todos no somos iguales" (12) en la "Otredad" del exilio.

Antes de proseguir con el abrigo del protagonista que refleja una mutación de identidad cultural y lingüística posmoderna, expliquemos que el vestir engloba el significado; 
es decir, el lenguaje de la moda como en el caso del "dandy" decimonónico o el "hippie" de los años sesenta. Como las palabras de un idioma, los accesorios excéntricos usado por ambos sujetos expresan la diferenciación o la protesta del individuo contra el establecimiento del aparato oficial. La vestimenta femenina o masculina, por el contrario, se conforma al significante, que no es otra cosa que la ropa distintiva que decide llevar puesto el individuo. De esta manera, se puede diferenciar el movimiento dialéctico entre el significado y el significante que separa al sujeto del abrigo de lo que una sociedad determinada le pudiera imponer en cuestión de estilo.

El propio narrador enfoca esta distinción lingüística entre el "ven como quieras" y el "iría de vestir" (17). El "ven como quieras" resalta la diacronía; o sea, la individualidad que caracteriza al sujeto en la manera informal que lleva la ropa sin la ocurrencia innecesaria de la evolución temporal de la moda, en contraste con el 'iría de vestir", la sincronía que cumple con la constitución y el funcionamiento del lenguaje de la moda. Por ley diacrónica, el individuo sigue el curso del tiempo, pero antes se remonta a él, mientras que ley sincrónica se impone al sujeto por la sujeción al uso colectivo. Entre ambas direcciones, fluctúan las oposiciones lingüísticas que crean la diferenciación de la moda.

El narrador también considera este abrigo como una "representación simbólica un tanto novelesca" que va acompañada de las "pérdidas simbólicas" del traje de novia y la máquina de escribir $(120,121)$, recuerdos del "ayer" en Cuba que repercuten en el móvil discursivo de la escritura. Estilísticamente hablando, los paralelismos trazados implican un enfrentamiento entre tres símbolos que se aproximan por ser opuestos o semejantes y aún constituyen simetrías del discurso narrativo en la formulación sígnica del destierro ${ }^{8}$.

Durante la tramitación en Miami para el viaje de relocalización a Nueva York, el protagonista y su esposa reciben ropa gratuita de una agencia protestante. Si el abrigo negro de Amanda no tenía forma por ser ancho y largo hasta los tobillos, el del narrador evocaba una era prehistórica. La teatralidad del detalle resulta en histrionismo por su dosificación lúdica: "Una cucaracha le había comido el borde de la manga y el cuello, de pretencioso y grotesco terciopelo, tenía ásperos espacios redondos y ovalados" (21). Las consecuencias de esta primera decisión escénica nos permitirá explicar cómo la inserción del abrigo se escribe en la primera parte del relato y de qué manera la disonancia de este objeto regalado afecta la psiquis del protagonista ante la percepción antiestética y antihigiénica que gratuitamente exhibe en su condición exílica. Se cuestiona al mismo tiempo repetitivamente: "Íbamos a dejarnos llevar por un par de abrigos? ¿Íbamos a dejar que unos abrigos determinaran el rumbo que tomarían nuestras vidas?" (22).

Siempre teniendo en cuenta el abrigo del narrador, esta vestimenta contiene un gran valor sociológico y económico, cuya función diacrónica se convierte en un signo polisémico intencional en el significado del discurso. Así, como hecho empírico delata las circunstancias históricas en la que se encuentra el refugiado político, debido a la penuria que padece, a lo que se debe añadir el desaliño de la apariencia del protagonista, el otro significado antiestético y antihigiénico subyacente en el texto de Montes Huidobro ${ }^{9}$. De ahí, la importancia asociativa de este abrigo en la dialéctica diacrónica y sincrónica que se unifica sin interrupciones a lo largo del hilo narrativo. Como se ha expuesto, las prendas de vestir funcionan de modo sistemático, o como señalaría Barthes (2006: 8), forman una "historia," un "acto individual" y, al mismo tiempo, son partes de una institución colectiva social con funciones clarificadoras. 
Junto a la sociología y la economía del espectáculo que el abrigo emana, el lector se percata de las vicisitudes del protagonista y de Amanda en la comprensión del idioma en el nuevo país que los acoge. En su búsqueda de albergue en la gran metrópoli, el narrador saca a relucir el "sentido fonético" de un "acento dentro de otro acento", el de Nueva York. Logra asociar el proceso de asimilación cultural provocado por la disonancia del modo de vestir y de lucir con la emulación lingüística de la oralidad del inglés. Nótese ahora cómo los factores físico-descriptivos encaminan hacia el derrotero inescapable del refugiado cubano ${ }^{10}$, deseoso de integración en la "Otredad" de la nación de asilo, mediante un breve análisis de ortología, que erosiona indefectiblemente el contacto con la nueva cultura ${ }^{11}$ :

\footnotetext{
[...]Amanda decidía pronunciar con la mayor propiedad con el acento auténtico, pero no hacía otra cosa que empeorar la cosa, como si aquella pronunciación fuese un insulto, además con nuestro aspecto estábamos obligados a tener un acento repugnante dentro de [otro] acento. (36)
}

Tengamos en cuenta que la mayoría de las veces la grafía en inglés está en desacuerdo total con la pronunciación. Por esta razón, hay que modificarla para conformarla al signo gráfico.

En los efectos de este desacuerdo, radica, en mayor grado, el exorcismo lingüístico que experimenta Amanda ante los oyentes que no comprenden del todo el sentido de un "habla" (parole), un acto individual distinto, a pesar de que se trata de una misma "lengua" (langue), el accesorio lingüístico colectivo del pueblo en los Estados Unidos.

En cierto momento, cuando se refiere a los dramaturgos del exilio, Montes Huidobro sostiene que estos asedian a los protagonistas "víctimas de temblores neurológicos" con un marcado carácter existencialista que obsesivamente les da una "dimensión orgánica al estado mental" (2010: 247). Más concretamente, para Yara González Montes, en Desterrrados al fuego, se intensifican las "crisis físicas y psicológicas", un "acto de exorcismo exílico" que refleja el desajuste emocional que vive el personaje (2007: 212). Opinamos que es debido a ello que con el ritual del abrigo se atenúa el cerco de la psiquis del protagonista, el "exilio interior", llámense sus "moradas interiores", cuya culpabilidad descansa en "barreras intelectuales y afectivas" dentro de otro conjunto cultural (Ilie 1981: 31$)^{12}$.

Imposibilitado de encontrar trabajo y evitando recurrir al suicidio como secuela de la conciencia de la soledad que lo invade, el narrador se refugia en el banco de un parque donde se sienta. Desde allí, observa a los vagabundos que lo frecuentan y, en especial, sobresale uno, cuyo nombre nunca menciona, pero con el que se emparenta transitoriamente mediante un "abrigo idéntico" al suyo, "más atractivo, más antiguo", convertido ya en "reliquia histórica" (57); réplica deteriorada del que llevaba encima. El aspecto manchado y sucio del abrigo del sujeto le produce una náusea existencial desintegrada en crisis y en caos, el "resultado de un vómito" en estado de pudrición organizada" y "descomposición putrificada" (58) cuando intelectualiza y universaliza la costra en la tela del ropaje. ${ }^{13}$ En su condición agónica de expatriado y en búsqueda de interacción dialógica, lo que en realidad no fructifica en la obra ${ }^{14}$, la fuente sígnica de la vestimenta del vagabundo despierta en él "anhelos infinitos de emulación" que ontológicamente reflejan las "señales de miserable existencia humana" (57).

Barthes ha explicado que los accesorios que vestimos se vinculan, interna y externamente, con la apariencia corporal (2006: 34), cuestión epistemológica que entra en juego en la novela de Montes Huidobro, lo cual le da un inusitado significado al texto. Surge así, repetidamente, el tema de la impureza del cuerpo que no sólo se entrelaza mediante el abrigo, sino que eleva la plenitud de la suciedad a la condición metafísica del hombre. 
Detrás de esta preocupación intelectual y antiestética del protagonista que ensaya, novela o desea novelar con las ausencias / presencias de la máquina de escribir y el traje de boda, la especulación explícita en la siguiente instancia discursiva está en desacuerdo con el medio que lo rodea, sobre todo, cuando busca su alteridad: "La podredumbre humana era un universo que tenía la dimensión inmensurable del espacio, aunque podría estar encerrada en las mágicas circunstancias del abrigo" (61). ¿Quién es el hombre? ¿Cuál es su sitio en el universo? Estas eran dos interrogantes fundamentales de Miguel de Unamuno en su pensamiento filosófico de la existencia humana, preocupación que se observa en la novela de Montes Huidobro. Junto a la soledad, el vagabundeo y la depresión exílica que lo abate, el personaje relata la descomposición orgánica de su estado de ánimo en crisis y causante de la falta de aseo personal que su figura personifica, pero que también lleva por dentro en términos de angustia, lo que también hace cuando se compara con el vagabundo del parque.

El personaje torna ahora la mirada hacia su intimidad agonizante en tono revisionista, recapitulativo y autorreflexivo desde lo que consideramos el perspectivismo de Unamuno, para quien la existencia es angustia, ese "exilio interior" en la novela de Montes Huidobro. La incertidumbre por la futilidad de esfuerzos por la búsqueda de empleo, así como la poca comunicación existente y el constante alejamiento entre él y Amanda conducen hacia la fragmentación de la conciencia del expatriado en el encapsulamiento que describe:

Era como si yo estuviera encerrado en aquel abrigo que conservaba mi suciedad amorosamente, y como si la permanencia de esa suciedad sobre mi cuerpo fuese tan ajustada que el mal olor que iba acumulando no saliera hacia afuera. Podría dormir un poco la mañana y salir a buscar trabajo más tarde [dijo Amanda]. (64)

Los sentimientos del protagonista ocasionalmente actualizan el desarraigo histórico y geográfico del pasado, mientras narra el presente con gesto de asco, vacío y miedo, síntomas que pudieran aparecer en la problemática de cualquier refugiado político. En el fondo, ambas temporalidades son únicamente un punto de enlace entre dos momentos, un instante, sentido y expresado con el fluir del tiempo psíquico. Es la crisis psicológica y existencial que padece, que en el texto se llama "desintegración gratuita", "putrificación” de la materia o "legítima compenetración" con el credo de los "patriarcas de la soledad", los vagabundos afines del parque y con los que establece una tajante analogía ante el caos que los rodea. Por este motivo, suele resignarse a una vida sin finalidad posible y asimismo olvidarse de sus desdichas.

En la sacudida metafísica de la voluntad, la abulia y la agonía unamunianas, el narrador sufre de un "trauma recurrente", alteración orgánica que pasa de la "hipertrofia de la acción a la hipertrofia de la parálisis" (73). Jorge Chen Sham constata que en Unamuno este pathos se condensa en un proceso de concientización que se impone "como categoría existencial", experimentado ante la "precariedad y la conflictividad de la existencia humana" $(111,113)$. Algo parecido a lo estipulado por el crítico se evidencia en la obra del autor cubano. Al igual que Unamuno en Del sentimiento trágico de la vida, en el pensamiento de Montes Huidobro, concebido a través del protagonista del Desterrados al fuego, la existencia humana es el gran producto de Dios, pese a los conflictos disonantes entre la esencia y la existencia, el ideal y la realidad y el fervor sanchopancesco de la inmediatez y la complitud, giros temáticos estructurados en ambos autores. Citamos ahora del autor vasco en el texto antes mencionado: "Y necesitamos a Dios para salvar la conciencia; no para pensar en la existencia, sino para vivirla" (1999: 179).

Después de la condición orgánica que el protagonista transparenta por medio del abrigo, sus síntomas psíquicos se raciocinian a través de los sentidos del olfato, la vista y el 
tacto. En la concientización de su inmovilidad, "sentía que los nervios trasmitían aquellas sensaciones al cerebro con desproporcionada lentitud, como si la sensación procediese de un distante planeta" (93). Más aún, en su subconciencia percibe un idioma ininteligible, posiblemente procedente de una bandada de pájaros, la imagen acústica que va a prevalecer en esta sección del relato. Escucha el ruido remoto de un hosanna que procede del fondo de un tabernáculo, acompañado de otras criaturas que le asediaban en vuelo presuroso. Sin entrar en explicaciones freudianas o en la versión de Alfred Hitchcock, uno de los cineastas favoritos de Montes Huidobro, el narrador decide hacer una reconstrucción de este lenguaje procedente de la ligurgia y de las aves para comprender su condición trágica. Alejado de su centro vital, lo único que le resta es regresar a este, mediante una explicación lingüística desconcertante:

\footnotetext{
Y no es que importe en lo más mínimo esta transcripción fonética, ya que en el fondo es falsa. No obstante, en esa falsedad reside su significado: volvía pero buscaba en aquella comunicación el modo de quedarme. Lo trágico de mi situación recrudeció en mí un interés ficticio a la naturaleza intelectual por los estudios lingüísticos (108)
}

Por un lado, al acudir al verdadero "significado", el personaje busca en la comunicación linguiística una manera de pertenencia normalizada en el exilio, el "modo de quedarme" en los Estados Unidos, aunque no lo encuentra. Pero también ejecuta el despojo de su lengua, de su vestido lingüístico, como lo hace con el abrigo pestilente hacia el final de la narración. Por el otro, hay que notar que las estructuras básicas de la linguiística determinan las máscaras del autor frente al signo referencial de su escritura. Añadamos además que Montes Huidobro, ex-profesor de la Universidad de Hawaii, conservaba y aún conserva el dominio del discernimiento entre los estudios lingüísticos y los literarios, nota personalísima que nos puede asistir a interpretar la novela como modo de acercarse al conocimiento de la existencia humana: “No era esta la mejor manera de comprender a mis semejantes”, y salir así del "espanto del aislamiento" sepultado "en el abrigo" (108).

Bajo el disfraz lingüístico, el narrador lleva a cabo "investigaciones fonéticas" que considera "arbitrarias", la arbitrariedad del signo que postulaba el lingüista Ferdinand de Saussure. En los lineamientos de Saussure, lo arbitratio no da la idea de que el "significante depende de la libre elección del hablante", sino que, por el contrario, es "inmotivado con relación al significado, con el cual no guarda ningún lazo natural” (131). El ejercicio facultativo de la fonética propiamente dicho estudia el aspecto intencional del análisis descriptivo de los sonidos, y cómo sólo funcionan enlazados a otros del sistema. Basado en esto, el narrador intenta reconstruir sus propios sonidos y vincularlos a otros, tarea imposible para él y un pretexto de su miedo a lo imprevisto que le produce un desconocido placer. La fonación a la que alude el personaje asienta la condición fundamental de la silabación (Saussure 120).

Debido a esta cadena fónica creada por el narrador, inventa además un diccionario con combinaciones silábicas, hecho que comprueba el postulado anterior de Saussure, pero comprende que el proceso es absolutamente "anticientífico" y respondía a un "imperativo psicológico" (109). Se observan, pues, rastros psíquicos, cuya representación nos da el testimonio de una imagen auditiva: "en toda palabra existe el residuo de nuestra propia identificación sonora" (109). Contradictoriamente, reconoce que el deseo de comunicación lo aisla, pese a que actúa acorde con su anhelo de incomunicabilidad. Ante tal paradoja, concluye con un planteo semiótico y exegético concreto de una iamgen acústica: "Yo prefería inventar a mi modo y manera, creando un lenguaje mediante una interpretación arbitraria del de ellos [el 
de los pájaros]" (109). Según Saussure, sonidos como estos nunca son "elementos orgánicos de un sistema lingüístico", sino que impresionan a ciertos oídos por una "sonoridad sugestiva" (132).

Poco antes del cierre del relato, el protagonista participa en el aeropuerto de Nueva York en un espectáculo de Mandrake el Mago, quien lo sube al escenario como si fuera "Charles Chaplin haciendo de Canillitas" (178), intertextualidad lúdica que salpica el texto mediante la risa / burla. Seguida la conclusión de este acto cómico, el mago transforma al personaje con el "cambio de traje", vestido de forma impecable y el cuerpo limpio. Se despoja del abrigo mugriento "con absoluto desconocimiento de la moda" (179), una vez más la diacronía del lenguaje en la novela, puesto que de la imagen de la palabra abrigo no queda nada. Se posesiona de una chaqueta de piel negra ajena colgada en un percha del lugar, otro simulacro más que apoya el disfraz, una nueva máscara que adquiere el protagonista. Mientras se trastocan los papeles protagónicos, aparece en el bolsillo un par de billetes con un vuelo a Honolulu, un "salto económico feliz hasta el medio del Pacífico" (201).

La imagen de la mismidad del sujeto pestilente y antihigiénico, producto de un exilio convulso y de fatiga psíquica e existencial, desemboca en la fragmentación del otro, que finalmente, en el cambio de ropaje, juega un papel diferente casi al final de la obra. Constituye el desplazamiento a la alteridad que se decanta hacia la hibridez posmoderna y que gobierna todas estas permutaciones textuales en un vuelco de funciones categóricas distintas.

En un trámite de metaficción y metacrítica novelística, al recordar la pérdida de la máquina de escribir confiscada en Cuba, detectamos la estética de la recepción al final del relato. Mediante ella, se garantiza la interacción confabulada entre el "autor", el 'lector" y el "texto". Este último juega un papel vital en la obra, debido a las digresiones numerosas del narrador que lo nombra. Por eso, le corresponde a este lector aquilatar el valor artístico de la novela:

\footnotetext{
Nunca más ha vuelto a poner dos palabras juntas y esto que tan mal escribo no es otra cosa que espejismo del que leyere (ya que en moderna técnica novelesca el lector completa el cuadro con lo que omite el novelista), y que todo mérito que se le ponga o que se le quite nunca sera mío a los ojos que me miren (201)
}

Incidentalmente, en las últimas peripecias de la narración, el protagonista, transformado en figura autorial, adquiere una nueva identidad: la del escritor que ha completado su novela que el lector lee. En el enunciado anterior, se le ha otorgado a este lector un pacto de confianza para que emita su juicio. Por último, Amanda hace su reaparición en Hawaii bajo el apartado "El ave Fénix". La personificación de la figura mítica, símbolo del fuego en la hoguera, se puede intepretar como el círculo ardiente de la creación novelesca del autor. Pero además, Fénix renace de las cenizas, de las propias palabras del narrador, acompañadas del mismo renacimiento súbito de Amanda que se ha mantenido alejada del protagonista a lo largo de la narración. Gracias al mito, ocurre la transformación evolutiva de la pareja, engranaje recíproco que disfrutaban en Cuba, mucho antes de la desintegración y el caos que todavía padece la Isla.

Dramaturgo, poeta, ensayista apasionado, meditador de la agonía e inquietador de la conciencia exílica cubana, Matías Montes Huidobro en Desterrados al fuego le da a la obra un sello inconfundible en la novelística contemporánea. Libro distinguido con una mención por el jurado del "Concurso Primera Novela" en México, exhibe una crónica diaspórica llena de recuerdos e interrogantes, nostalgias, perplejidades y de posturas personales. En el sentimiento trágico del texto, brotan explícitamente las bases ontológicas de la angustia ante la "Otredad," un "exilio interior" que va parejo a un abordamiento semiótico en las entrañas de la lengua y la palabra, el signo de ese "abrigo" que nos cobija en nombre de la libertad. 


\section{Notas}

1. De ahora en adelante, se citará de esta edición con el número de la página.

2. Véase también William Gass (1990: 1-8). Según Gass, la falta de pertenencia y la pérdida de identidad constituyen dos experiencias innatas al exiliado.

3. Michael Ugarte explica que el término "desterrado" implica un desenterramiento que pierde el enlace entre la tierra y el alma (1989: 10).

4. Paul Ricoeur opina que la memoria individual (o colectiva) es producto de lo enunciado gracias al recuerdo (1985: 132).

5. Para William Siemen, el abrigo representa "la piel de un animal dentro del cual tendrá que morirse para renacer con una identidad nueva" (2007: 18).

6. Umberto Eco favorece la interpretación textual por medio de la cual el "lector modelo," como lo llama, es cómplice partícipe de la obra literaria.

7. En el ensayo "El exilio invisible" (mi traducción), Guillermo Cabrera Infante toca sobre esta cuestión de la pérdida de identidad (1990: 34-41).

8. Según la hipótesis de Carlos Bousoño, se trata de un "paralelismo conceptual" (1966: 212), siendo el concepto en la novela de Montes Hudibobro la concreción temática del exilio.

9. Consúltese la estética del vestir y el cuerpo en la modernidad como signo en el artículo de Ken Montague (1994: 91).

10. Señala Lourdes Gil que la lengua es un un espacio determinado que concibe metáforas de angustia y pérdida, lo extraño y la marginalidad, o una "malla intrincada de libertad y revelación" (1998: 180).

11. En un sentido más amplio, Robert Edwards indica que el desplazamiento espacial del exiliado se ajusta a las continuidades culturales y sociales de dicho traslado en tanto el sentido de la "identidad" (1988: 24-27), la identidad lingüística en la novela de Montes Huidobro.

12. Sobre un asedio psicológico del escritor y el exilio, véase el libro de Bettina Knapp (1991).

13. Para la crisis y la desintegración del sujeto en la obra de José Camilo Cela, véase el artículo de Montes Huidobro, traducido por el que aquí escribe.

14. No existe aquí, sin embargo, la "dialogía bajtiniana," en la que la literatura puntualiza la búsqueda del diálogo, según los planteamientos de Iris Zavala (1991: 63).

\section{Bibliografía}

Abellán, José Luis. 1987. "El exilio como categoría cultural. Implicaciones filosóficas". Cuadernos Americanos. 1(1): 42-57. 
Alvarez-Borland, Isabel. 1998. Cuban-American Literature in Exile: From Person to Persona. Charlottesville: U of Virginia P.

Barthes, Roland. 2006. The Language of Fashion. (Trad. Andy Stafford). Oxford: Berg.

Bousoño, Carlos. 1966. Teoría de la expresión poética. (4ª ed). Madrid: Editorial Gredos.

Cabrera Infante, Guillermo. 1990. “The Invisible Exile”. Literature in Exile. (Ed. John Glad). Durham: Duke UP.

Chen Sham, Jorge. 2001. Radiografía del sujeto agónico: culpa y transcendencia en la novelística de Rima de Vallbona. San José: Perro Azul.

Eco, Umberto. 1981. Lectura in fabula. Barcelona: Lumen.

Edwards, Robert. 1988. "Exile, Self, and Society”. Exile in Literature. (Ed. María Inés LagosPope). Lewisburg: Bucknell UP. 15-31

Gass, William. 1990. "The Philosophical Significance of Exile". Literature in Exile. 1-8.

Gil, Lourdes. 1998. "Against the Grain: Writing in Spanish in the USA". Remembering Cuba: Legacy of a Diaspora. (Ed. Andrea O’Reilly Herrera). Austin: U of Texas P.

González Montes, Yara. 2007. "La ensayística en la obra literaria de Matías Montes Huidobro”. Matías Montes Huidobro: su obsesión por la escritura. Ed. Yara González. Miami: Ediciones Universal.

Ilie, Paul. 1981. Literatura y exilio interior: escritores y sociedad en la España franquista. Madrid: Fundamentos.

Knapp, Bettinna. 1991. Exile and the Writer. Esoteric and Esoteric Experiences. A Jungian Approach. Philadelphia: The Pennsylvania UP.

Lurie, Alison. 1992. "Clothing as a Sign System”. The Language of Clothes. London: Bloomsbury.

Montes Huidobro, Matías. 2010. Cuba detrás del telón. Insularidad y exilio (1969-1979) .Miami: Ediciones Universal.

1975. Desterrados al fuego. México: Fondo de Cultura Económica.

1991. "Monad, Quantum and Entropy in Cela's Chaos". (Trad. Luis A. Jiménez). Ometeca. 2 (2): 55-70. 
Montague, Ken. 1994. "The Aesthetics of Hygiene: Aesthetic Dress, Modernity and the Body as Sign”. Journal of Design History 7(2): 91-112.

Ricoeur, Paul. 1985. Memory, History, Forgetting. Trad. K Blomey y D. Pellaver. Chicago: Chicago UP.

Said, Edward. 1990. "Reflections on Exile". Out There: Marginalization and Contemporary Cultures. (Ed. Russell Ferguson et al). Cambridge: The M.I.T. P.

Saussure, Ferdinand de. 1955. Curso de lingüística general. Trad. Amado Alonso. Buenos Aires: Editorial Losada.

Siemens, William. 2007. “Transformaciones paralelas en Desterrados al fuego”. En: González (ed), 17-25.

Ugarte, Michael. 1989. Shifting Ground: Spanish Civil War Exile Literature. Durham: Duke UP.

Unamuno, Miguel de. 1999. Del sentimiento trágico de la vida. (3 ${ }^{\mathrm{a}}$. ed). Madrid: Editorial Espasa-Calpe.

Zavala, Iris, M. 1991. Unamuno y el pensamiento dialógico. Barcelona: Editorial Anthropos. 
